\title{
Reticulocytes Have a Higher Resistance to Complement Lysis than Erythrocytes
}

\author{
Salima Sadallah Shlemen Hanno Jürg A. Schifferli \\ Department of Biomedicine, University Hospital Basel, Basel, Switzerland
}

Old RBC have been shown to express less decay-accelerating factor (CD55), CD59 and complement receptor 1 (CR1, CD35) than young RBC [1-5]. All 3 proteins are known to regulate complement and CD55 and CD59 are essential for the protection of RBCs against autologous lysis by the continuous complement activation that takes place in plasma in the vicinity of RBCs [6-8]. Paroxysmal nocturnal haemoglobinuria, in which CD55 and CD59 are lacking because of a deficient synthesis of their GPI anchor, is the best illustration of their protective role [9]. Whether CR1 protects the RBC itself is uncertain, although when transfected to $\mathrm{CHO}$ cells, CR1 has been shown to reduce complement-mediated lysis [10]. Reticulocytes express approximately 3-fold more of all 3-complement regulators when compared to erythrocytes $[2,4$, $5,11]$ (here we define erythrocytes as non-reticulocytes, and $\mathrm{RBC}$ as the total population). To our knowledge, whether these differences would be of biological significance has not been tested. We therefore set out to measure reticulocytes before and after haemolytic assays performed with 4 combinations of $\mathrm{ABO}$ incompatibility, using different concentrations of serum and incubation times, as well as 2 temperatures $\left(25\right.$ and $\left.37^{\circ} \mathrm{C}\right)$.

\section{KARGER}

Fax +4161306 1234 E-Mail karger@karger.ch www.karger.com
(C) 2010 S. Karger AG, Basel 0001-5792/10/1233-0153\$26.00/0

Accessible online at:

www.karger.com/aha
We defined RBCs as the population of erythrocytes + reticulocytes. We used EDTA blood from group A or B healthy donors $(n=4)$. The blood was centrifuged for 10 min at $4^{\circ} \mathrm{C}$ and $500 \mathrm{~g}$ and the plasma removed. The cells underwent $4 \%$ dextran sedimentation for $30 \mathrm{~min}$ on ice in order to remove the white blood cells. The RBCs were then washed 3 times with cold $0.9 \% \mathrm{NaCl}$. They were counted and adjusted to the concentration of $7 \times 10^{10}$ cells $/ \mathrm{ml}$.

The sera used as sources of antibodies and complement were from Rh-positive donors with blood group $\mathrm{O}$. The sera were collected and used on the same day.

Four samples of RBCs from normal donors with blood groups A and B were exposed to various concentrations of different sera from blood group O donors in a simple haemolytic assay comparable to the standard $\mathrm{CH} 50$ assay. Three parameters were varied: the serum concentration, the time of incubation, and the temperature. The percentage reticulocytes was determined before and after haemolysis, and the percentage of cells remaining after haemolysis was measured. Briefly, $10^{8} \mathrm{RBC}$ were exposed to different concentrations of serum. $\mathrm{NaCl}$ was added as negative control. Total lysis was achieved by adding dis-

Dr. Salima Sadallah

Department of Biomedicine, University Hospital Basel

Hebelstrasse 20

$\mathrm{CH}-4031$ Basel (Switzerland)

Tel. +41 61265 3262,Fax +4161265 2350,E-Mail salima.sadallah@unibas.ch 
Table 1. Relationship between percentage reticulocytes and percentage lysis at $37^{\circ} \mathrm{C}$

\begin{tabular}{llccccc}
\hline & \multicolumn{1}{l}{ Lysis, \% } & & & \\
\cline { 2 - 6 } & 0 & $24.5-26.3$ & $55.2-57.1$ & $67.4-71.4$ & $85-89$ & $91.9-96.1$ \\
\hline Reticulocytes, \% & $0.8-1.3$ & $1.0-1.6$ & $1.5-2.5$ & $2.1-3.5$ & $2.4-4.5$ & $2.7-6.5$ \\
Increase in reticulocytes, \% & 0 & $23.1-27.3$ & $75-100$ & $92.3-172.7$ & $172.7-281.8$ & $237.5-400$ \\
\hline
\end{tabular}

Haemolysis was measured after $45 \mathrm{~min}$ incubation at $37^{\circ} \mathrm{C}$. The percentage of reticulocytes in healthy volunteers varies from 0.8 to 1.3 . This percentage increased proportionally to the percentage lysis. When 91.9$96.1 \%$ of RBC were lysed, the percentage increase of reticulocytes ranged from $237.5-400$, which is $3.375-5$ times the starting percentage of reticulocytes $(\mathrm{p}<0.01)$.

tilled water to the $\mathrm{RBC}$. The $\mathrm{RBC}$ suspensions were incubated under constant agitation at either $37^{\circ} \mathrm{C}$ for $25-45$ $\min$ or at $25^{\circ} \mathrm{C}$ for $65-125 \mathrm{~min}$. The samples were then centrifuged for $10 \mathrm{~min}$ at $4^{\circ} \mathrm{C}$ and $500 \mathrm{~g}$ and the RBC lysis (haemoglobin) in the supernatant determined by spectrophotometer at $554 \mathrm{~nm}$, using a Spectramax 190 photometer.

The reticulocyte counts were determined using the ADVIA 120T Hematology System (Bayer) in the $10^{8} \mathrm{RBC}$ population before exposure to different concentrations of serum and after lysis.

This index of resistance (iR) was calculated according to the following formula. It corresponds to the resistance of reticulocytes to lysis, with 1 being complete resistance (i.e. correlates inversely with the lysis of reticulocytes).

$$
\begin{aligned}
& \delta=\alpha X \frac{100 \%}{100 \%-\gamma} \\
& \mathrm{iR}=\frac{\varepsilon}{\delta}
\end{aligned}
$$

where $\gamma=$ measured lysis (in \%) of the RBC population, $\alpha=$ measured reticulocytes (in \%) of the RBC before lysis, $\varepsilon=$ measured reticulocytes (in \%) of the RBC after lysis, and $\delta=$ theoretical maximal amount of reticulocytes (in $\%)$ of the RBC after lysis.

The percentage reticulocytes increased with increasing lysis of total RBCs for all 4 samples of RBCs tested (table 1, fig. 1a), and this was observed at the various time intervals during the incubation (not shown) and at both temperatures tested(table 2 , fig. $1 \mathrm{~b}$ ). These data indicated clearly that reticulocytes were more resistant to lysis than erythrocytes. The resistance of reticulocytes was significantly higher at $25^{\circ} \mathrm{C}$ than at $37^{\circ} \mathrm{C}(\mathrm{p}<0.023)$.

To directly compare the resistance to lysis of reticulocytes versus erythrocytes, we calculated the iR of reticulocytes according to the formula above (fig. 2). The iR of reticulocytes illustrated the major difference between reticulocytes and erythrocytes: when $70 \%$ of the erythrocytes were lysed less than $20 \%$ of the reticulocytes were lysed. At the other end, when the lysis of ery throcytes was limited (up to 20\%), there was very low lysis of reticulocytes (fig. 2a). These differences were even more evident when the assays were performed at $25^{\circ} \mathrm{C}$ (fig. $2 \mathrm{~b}$ ).

The reticulocytes were strikingly more resistant to complement-mediated lysis than were erythrocytes. This should come as no surprise considering the significantly higher surface concentration of the 3 complement regulators on reticulocytes, which are 1-3 days old, versus erythrocytes, which have a half-life of 60 days. Whereas it is known that reticulocytes lose some membrane proteins by the release of vesicles when transforming into erythrocytes, the loss of the 3 complement regulators continues thereafter, as evidenced by the measures comparing young versus old erythrocytes. Although the precise mechanisms of these losses are not yet fully understood, much evidence suggests that this is due to ongoing vesiculation (ectocytosis) at the surface of the RBC, possibly related to attacks by different agents [1214]. In addition, all 3 regulators are lost similarly and are found on vesicles (ectosomes) released by in vitro aged erythrocytes [3]. Iida et al. [13] have elegantly shown that successful fixation of the C5-C9 complex does not lead invariably to lysis, but that this complex can be removed by active formation and release of ectosomes, which include the C5-C9 complex. In our assay it was not possible to define whether the resistance of reticulocytes was due to inhibition of $\mathrm{C} 5-\mathrm{C} 9$ deposition on the cells by the high concentration of complement regulators or to a higher capability of the cells to get rid of the C5-C9 by ectocytosis. The even higher resistance of reticulocytes at $25^{\circ} \mathrm{C}$ could have resulted from a reduced complement activation at $25^{\circ} \mathrm{C}$ (table 2 , fig. $1 \mathrm{~b}$ ) than at $37^{\circ} \mathrm{C}$ 
Fig. 1. Percentage of RBC lysis and percentage of reticulocytes after lysis. The figure represents percentage $\mathrm{RBC}$ lysis along with the percentage of serum. Each serum concentration corresponds the percentage of erythrocytes and of reticulocytes lysed. The RBC lysis was measured a after $45 \mathrm{~min}$ incubation at $37^{\circ} \mathrm{C}$ and $\mathbf{b}$ after $125 \mathrm{~min}$ incubation at $25^{\circ} \mathrm{C}$. Reti, Ery 1 and 2 are from the A blood group, Reti, Ery 3, 4 are from the B blood group.
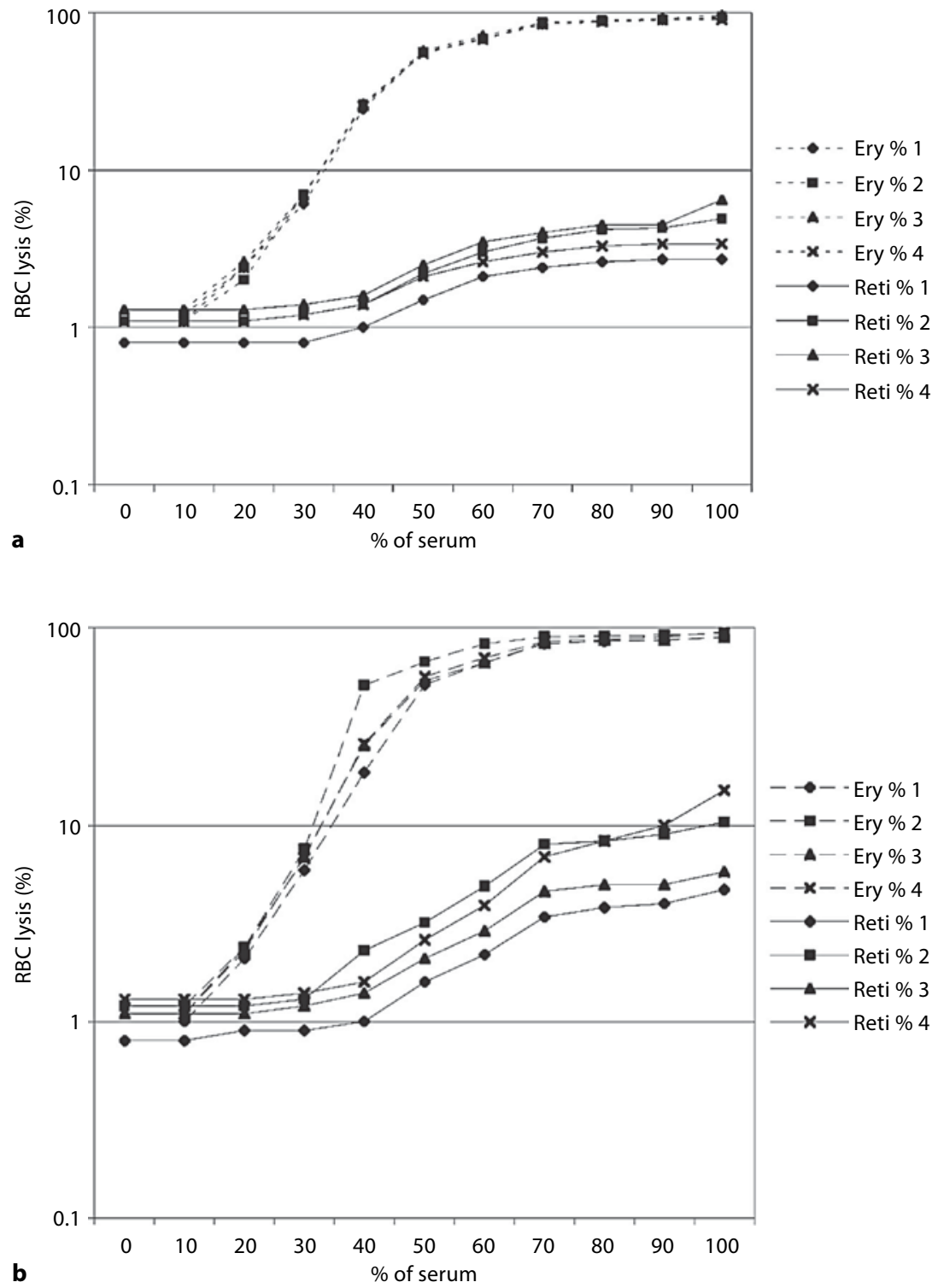

Table 2. Relationship between percentage reticulocytes and percentage lysis at $25^{\circ} \mathrm{C}$

\begin{tabular}{llccccc}
\hline & \multicolumn{2}{l}{ Lysis, \% } & & & \\
\cline { 2 - 7 } & 0 & $18.6-26.0$ & $51.7-56.9$ & $67.0-71.3$ & $83.9-89.0$ & $90.1-95.4$ \\
\hline Reticulocytes, \% & $0.8-1.3$ & $1.0-1.6$ & $1.6-2.6$ & $2.2-3.9$ & $3.4-8.3$ & $4.7-15.1$ \\
Increase in reticulocytes, \% & 0 & $23.1-27.3$ & $90.9-118.2$ & $163.9-200$ & $318.2-538.5$ & $427-1,061$
\end{tabular}

Haemolysis was measured after $125 \mathrm{~min}$ incubation at $25^{\circ} \mathrm{C}$. The percentage of reticulocytes increased proportionally to the percentage lysis. In the conditions where $90.1-95.4 \%$ of RBC were lysed, the percentage increase in reticulocytes ranged from 427-1,061 which represents 5.27-11.61 times the starting percentage of reticulocytes $(\mathrm{p}<0.0113)$. 
Fig. 2. iR of reticulocytes compared to the lysis of RBC. The $i R$ is a measure of the resistance of reticulocytes for different amounts of RBC lysis, with 1 describing complete resistance of reticulocytes and lower values a partial resistance. a Temperature $37^{\circ} \mathrm{C}$. In all conditions inducing $<20 \%$ lysis of the total RBCs, the iR of reticulocytes was 1 (corresponding to $100 \%$ resistance, i.e. no changes in the absolute number of reticulocytes). In conditions inducing around $60 \% \mathrm{RBC}$ lysis, the iR of reticulocytes was of 0.8 (corresponding to $80 \%$ resistance) only $20 \%$ of reticulocytes were lysed. When approximately $95 \%$ of $\mathrm{RBC}$ were lysed, the iR of reticulocytes was 0.3 (corresponding to $30 \%$ resistance) $70 \%$ of reticulocytes were lysed. b Temperature $25^{\circ} \mathrm{C}$. The differences in the resistance to lysis were even more evident at $25^{\circ} \mathrm{C}$. In all conditions inducing $<20 \% \mathrm{ly}-$ sis of the total RBCs, the $i \mathrm{R}$ reticulocytes was 1 (resistance of reticulocytes was $100 \%)$. In conditions inducing around $60 \%$ $\mathrm{RBC}$ lysis, iR of reticulocytes was of 0.85 (corresponding to $85 \%$ resistance) only $15 \%$ of reticulocytes were lysed. When approximately $95 \%$ of RBC were lysed, the $\mathrm{iR}$ of reticulocytes was of 0.5 (resistance of reticulocytes was of $50 \%$ ) only $50 \%$ of reticulocytes were lysed. Reti 1 and 2 are from the A blood group, Reti 3 and 4 are from the B blood group.
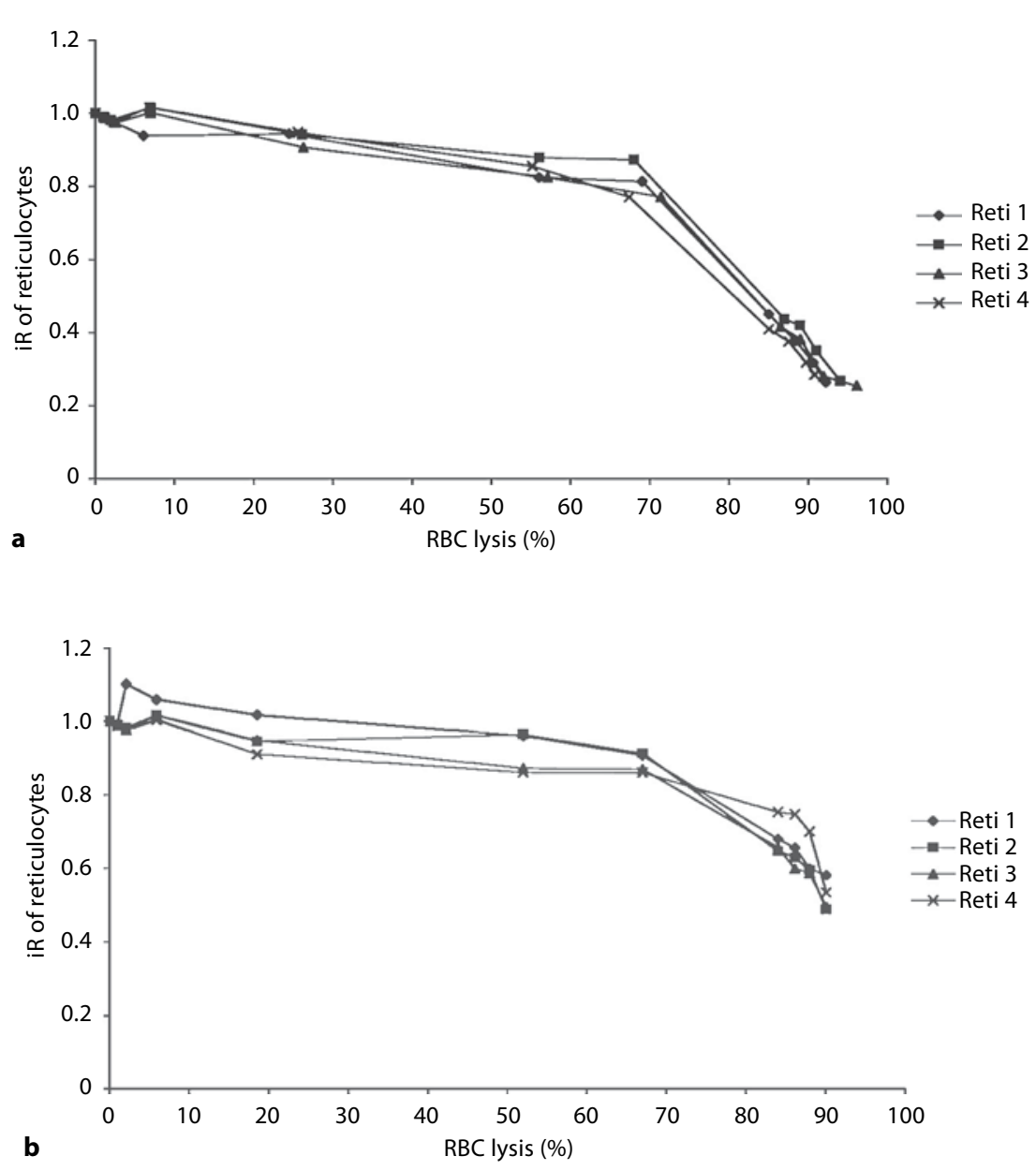

(table 1, fig. 1a). Thus, the specific mechanism(s) responsible for the increased resistance of reticulocytes remains to be defined.

In conclusion, the intrinsic property of reticulocytes to resist lysis distinguishes them from the general population of erythrocytes, and may also explain why reticulocytes continue to be released in the blood stream at high rates in haemolytic anaemia without being harmed in the bone marrow before release. Finally, in haemolytic anaemia, the lysis most probably occurs under limiting conditions, resembling the experiments performed with low serum concentration or at $25^{\circ} \mathrm{C}$. It is tempting to speculate that the 'reticulocytosis' observed under these circumstances (i.e. haemolytic anaemia) is not only due to enhanced production, which evidently occurs, but also to the intrinsic resistance of reticulocytes, which do not lyse under limiting conditions.

\section{Acknowledgments}

This work was supported by the Swiss National Foundation (grant 32000-116839), the Roche Foundation for Anemia Research, and Nora van Meeuwen Stiftung. 


\section{References}

1 Test ST, Butikofer P, Yee MC, Kuypers FA, Lubin B: Characterization of the complement sensitivity of calcium loaded human erythrocytes. Blood 1991;78:3056-3065.

$\checkmark 2$ Lutz HU, Stammler P, Fasler S, Ingold M, Fehr J: Density separation of human red blood cells on self forming Percoll gradients: correlation with cell age. Biochim Biophys Acta 1992;1116:1-10.

$\checkmark 3$ Pascual M, Lutz HU, Steiger G, Stammler P, Schifferli JA: Release of vesicles enriched in complement receptor 1 from human erythrocytes. J Immunol 1993;151:397-404.

-4 Rabesandratana H, Toutant JP, Reggio H, Vidal M: Decay-accelerating factor (CD55) and membrane inhibitor of reactive lysis (CD59) are released within exosomes during in vitro maturation of reticulocytes. Blood 1998;91: 2573-2580.
Lach-Trifilieff E, Marfurt J, Schwarz S, Sadallah S, Schifferli JA: Complement receptor 1 (CD35) on human reticulocytes: normal expression in systemic lupus erythematosus and HIV-infected patients. J Immunol 1999;162:7549-7554.

6 Ahearn JM, Fearon DT: Structure and function of the complement receptors, CR1 (CD35) and CR2 (CD21). Adv Immunol 1989;46:183-219.

7 Davies A, Simmons DL, Hale G, Harrison RA, Tighe H, Lachmann PJ, Waldmann $\mathrm{H}$ : CD59, an LY-6-like protein expressed in human lymphoid cells, regulates the action of the complement membrane attack complex on homologous cells. J Exp Med 1989;170: 637-654.

8 Lublin DM, Atkinson JP: Decay-accelerating factor: biochemistry, molecular biology, and function. Annu Rev Immunol 1989;7:35-58.

$\checkmark 9$ Parker CJ: Molecular basis of paroxysmal nocturnal hemoglobinuria. Stem Cells 1996; 14:396-411.

10 Makrides SC, Scesney SM, Ford PJ, Evans KS, Carson GR, Marsh HC Jr: Cell surface expression of the $\mathrm{C} 3 \mathrm{~b} / \mathrm{C} 4 \mathrm{~b}$ receptor $(\mathrm{CR} 1)$ protects Chinese hamster ovary cells from lysis by human complement. J Biol Chem 1992;267:24754-24761.
1 Miot S, Marfurt J, Lach-Trifilieff E, Gonzalez-Rubio C, Lopez-Trascasa M, Sadallah S, Schifferli JA: The mechanism of loss of CR1 during maturation of erythrocytes is different between factor I deficient patients and healthy donors. Blood Cells Mol Dis 2002;29: 200-212.

12 Stein JM, Luzio JP: Ectocytosis caused by sublytic autologous complement attack on human neutrophils: the sorting of endogenous plasma-membrane proteins and lipids into shed vesicles. Biochem J 1991;274:381386.

13 Iida K, Whitlow MB, Nussenzweig V: Membrane vesiculation protects erythrocytes from destruction by complement. JImmunol 1991;147:2638-2642.

14 Pilzer D, Gasser O, Moskovich O, Schifferli JA, Fishelson Z: Emission of membrane vesicles: roles in complement resistance, immunity and cancer. Springer Semin Immunopathol 2005;27:375-387. 